\title{
Connective knowledge: what we need to know about other fields to 'envision' cross-disciplinary collaboration
}

\author{
Nicky Priaulx ${ }^{1,2^{*}}$ and Martin Weinel ${ }^{3}$
}

\begin{abstract}
This paper centralises the question of what academics in higher education settings need to know about other fields to stimulate cross-disciplinary collaborative work. The concept of 'knowledge', while recognised as important within cross-disciplinary studies, has failed to be properly problematized. Little attention has been paid to what cross-disciplinary knowledge actors should possess, the purposes that knowledge might serve and few pause to consider the concept of collaboration itself, as an inherent source of situated learning. The result is recommendations about what researchers should 'know' that cannot be operationalised in practice. Highlighting a distinction between 'Of-Knowledge', entailing a detailed understanding of a field, and 'About-Knowledge', a rudimentary form of knowledge about fields, we explore two key points of the cross-disciplinary collaborative lifecycle to evaluate the needs, purposes, limits and possibilities of knowing. Noting that cross-disciplinary learning is a long process, and for which no pre-packaged 'knowledge' emerges to address the kinds of cognitive deficits that researchers typically identify, we argue that collaboration itself provides a non-substitutable venue for crossdisciplinary learning. In contrast, focusing on the point of 'envisioning' where specialisms are 'scoped out' and collaborative horizons 'mapped', we argue for efforts to be placed in enhancing researchers' 'About-Knowledge', a form of connective knowledge that extends researchers' basic knowledge about other fields prior to constructing collaborative projects. Critical for the aspirations of futures research, and the importance of fostering global, national, regional and local collaboration, we highlight how a little knowledge can go a long way.
\end{abstract}

Keywords: Connective knowledge, Cross-disciplinary collaboration, Of-knowledge, About-knowledge, Barriers and enablers, Envisioning

\section{Introduction}

Central to this paper is the question of what and how much academics in higher education settings need to 'know' about other fields and specialisms in the context of cross-disciplinary collaborative work. That this constitutes a novel query might be surprising given the volume of work within interdisciplinary studies literature that highlights the numerous epistemic and cognitive challenges involved in cross-disciplinarity collaboration. Nevertheless, a noticeable aspect of the literature is the degree to which the concept of 'knowledge' itself, while

\footnotetext{
* Correspondence: Priaulxn@cardiff.ac.uk

${ }^{1}$ Cardiff University LawLab Research Centre, Cardiff, UK

${ }^{2}$ Cardiff School of Law and Politics, Cardiff University, Museum Avenue,

Cardiff CF10 3AX, UK

Full list of author information is available at the end of the article
}

certainly recognised as important, has failed to be properly problematized. Little attention has been paid to the question of what cognitive stores or cross-disciplinary 'literacy' an actor might ideally possess for quite different points of the cross-disciplinary life-cycle. To think through this question in furtherance of developing useful strategies for enhancing our collaborative opportunities, this article seeks to cut new ground by highlighting the importance of distinguishing between two kinds of knowledge, 'Of-Knowledge' and 'About-Knowledge'. These can be briefly exemplified by two contexts which highlight the distinctive challenges that arise for researchers when different kinds of knowledge are absent. The first context involves actors from different disciplinary traditions or specialisms that are already connectedfor example, psychologists and sociologists-who attend a 
'collaborative' workshop on 'expertise', a concept that is central to both groups, yet fail to understand each other due to clashing conceptualisations of 'expertise' that is particular to each disciplinary domain. In contrast with the epistemic clashes described in the first context which relate to a deficit in knowledge of another field-the second context concerns an absence of knowledge about fields. For example, a group of engineers or computer scientists working on a problem domain that while having 'human users', believe that their technical knowledge of engineering or computer science is enough because they 'speak human' and 'already "know" what people think/do' ([49], p. 13). Or indeed, researchers come to believe that future studies "is primarily about "prediction" and "forecasting" to the idea that future studies can be nothing more than "ungrounded speculation", because the future is inherently unknowable' ([28], p. 24). This kind of knowledge deficit, about other fields, provides fertile ground for misconceptions about other specialisms, for actors exceeding their own field of expertise $[3,61]$ and importantly, for missed opportunities for valuable and important collaborations by virtue of a failure to understand the value of, and expertise inherent within other fields and specialisms.

As we highlight in this piece, these two contexts present cognitive challenges of quite different kinds. The first context does not concern a failure to understand the potential relevance that another field or specialism might have for collaboration, but rather entails a lack of knowledge of the particular and specific mechanics of that field: 'Of-Knowledge'. The second, in contrast, concerns a lack of 'About-Knowledge'-knowledge about fields that results in the failure of actors to see another field or specialism at all. Nevertheless, in respect of the literature, the distinction between these kinds of knowledges is rarely identified. Instead, where the problems of cross-disciplinary cognitive deficits are centralised, the focus tends to be on collaborative work-in-progress, and frequently on 'Of-Knowledge' strategies, resulting in generalised suggestions that simply amount to calls for researchers to 'know more' field-specific knowledge. While knowing more is desirable, the lack of consideration around what specifically needs to be known, and for what purpose(s), means that no strategy can be operationalised from this in practice. For us, the reason for this relates to the concentration of attention on barriers to cross-disciplinary work-in-progress, resulting in an overly simplistic diagnosis of a cognitive deficit for which "knowing more' appears to be the solution. Yet, as we seek to demonstrate in this paper, whether one's focus is on the question of how to initiate novel and innovative connections between actors who lack even basic insight into a range of other fields and sectors - or how to enhance existing cross-disciplinary collaborations, 'Of-Knowledge' strategies fall short of, or indeed, wildly exceed, what is required.
Given the inherently collaborative and interdisciplinary nature of futures research, which invites the widest range of actors from multiple jurisdictions, sectors, industries and communities to harness collaborative creativity for insights and practical solutions for different futures issues' [30], the current contribution problematizes the 'how to' of optimising collaborative connectivity by paying close attention to different points of the collaborative life-cycle-from the initiation of connections to the fostering and enhancement of connections already made. As we consider here, these different stages implicate radically different kinds of 'know-how', for which distinctive strategies of knowledge acquisition are called into play. With the aim of extending futures research and broader cross-disciplinary collaborative efforts, we focus on enabling factors, realistic thresholds and the generation of a positive agenda for enhancing connectivity. Drawing upon insights from the Studies of Expertise and Experience $[19,61]$ to evaluate the limits of knowledge acquisition in this context, and building on the theory of 'envisioning' (Martin M, 2015, Architectural discourse of socio-technical systems, Unpublished) which centralises the pre-collaborative point at which actors 'scope out' specialisms, map collaborative horizons and make connections between different fields, we move through a simple framework to evaluate what needs to be known at different stages of the cross-disciplinary life cycle. With this more purposeful enquiry, we note that at the point of seeking to initiate connections, the aim needs to be for actors to possess the widest range of fields in sight in furtherance of path-breaking and non-traditional forms of cross-disciplinary collaboration. For this, the 'know-how' in question should be designed to enable actors to see a wide horizon of fields, specialisms and problem domains by which to make connections between their own expertise and the work of others. Identifying different possible levels of cross-disciplinary knowledge, and centralising the aim-notably to initiate and stimulate new and novel connections between actors from different sectors and fields-helps us to settle on a practical and fairly rudimentary level of 'connective knowledge': 'About-Knowledge'. Aiming purposefully low in our expectations of what researchers can learn up front about other fields, we advocate 'About-Knowledge' in order to provide basic insight into some of the problem domains and approaches that populate other fields and specialisms. We do not attempt to quantify or prescribe 'how much' 'About-Knowledge' it would be ideal for researchers to possess; instead, our aim is to shift the debate away from overly demanding and impractical ideas about what researchers should know, in favour of a lower and practical threshold for cross-disciplinary cognition. Drawing on insights from a range of fields that 
illustrate the enabling effect of basic cross-disciplinary cognition, we also make some preliminary suggestions as to the ways and means that such connective 'About Knowledge' can be delivered and achieved. We dismiss recommendations for researchers to acquire deeper cross-disciplinary Of-knowledges in advance of crossdisciplinary engagement as impractical, unrealistic and even excessive. In similar force, in evaluating the kind of know-how necessary for later stages of the collaborative life-cycle, with cross-disciplinary/sectoral connections already instigated, we also highlight concerns with the recommendations of researchers that actors would benefit from 'knowing more' Of-Knowledge, involving more granular insight into the operational workings of a specific field. Again, a clear focus on the purpose of actors collaborating in the first place, and the essential bargain that sits central to collaborative work-notably the combining of knowledge and expertise-proves critical for thinking through what, and how much or little, researchers need to know about alternative fields in order to construct cross-disciplinary 'bridges'. As we seek to show, analysis of the collaborative ideal and how cognitive factors are implicated in this process, promotes a stronger theorisation of the kinds of knowledge that prove to be enabling to, excessive for, or even destructive of collaboration. Noting that cross-disciplinary learning admits of a longer journey entailing the gradual acquisition of cross-disciplinary knowledge through active cross-disciplinary practice, the thrust of our argument is that in the context of aspirations to connect disciplines, fields and sectors, as well as to maintain and enhance them, a little knowledge is likely to go a long way.

\section{Barriers: the great unknowns}

[I]nterdisciplinary efforts inevitably meet barriers, be they structural, cognitive or normative. The questions that should be discussed, then are what these barriers are, what makes each of them a barrier and how can they be surpassed? ([9], p. 447).

Despite the intense interest in, and greater emphasis upon cross-disciplinary/-sectoral collaborative work $[9,46,56]$, there remains a substantial gap in the interdisciplinary literature around how cross-disciplinary collaborations are initiated ([7, 65], p. 23) and the factors, capacities and competences that prove particularly influential in that regard. While the aim of many researching within interdisciplinary studies is to identify pathways for enhancing cross-disciplinary collaboration and innovation, the conversation has largely stalled at the point of evaluating barriers. From the now voluminous literature highlighting the challenges, risks and benefits of cross-disciplinary and -sectoral collaboration [50], one can identify myriad factors that operate to impede interdisciplinarity. To a significant degree, the literature around interdisciplinarity has taken on the appearance of a 'silo' genre, replete with references to the numerous structural, cognitive and normative barriers that serve to estrange disciplinary actors from one another. While highlighted as challenges, in real terms, many of these barriers are seen as social by-products of the processes entailed in developing expertise. On the one hand, our estrangement from others is a consequence of the kind of intense immersion within a specialisation that is necessary for the acquisition of disciplinary expertise $[9,15]$. On the other hand, our depth of immersion and expertise in one field also situates us as outsiders in respect of other specialist areas and fields. The outsider status that we experience, geographically, socially and culturally from others fields, means that other expert domains appear as 'foreign', with occupants that speak different languages, possess different ontologies, goals, purposes and forms of life. By virtue of our lack of socialisation within those expert domains or 'epistemic communities' [15], we will necessarily have limited insight into, or appreciation of, the normative, ethical and ontological commitments of those fields.

In the context of the cross-disciplinary collaborative ideal, while our estrangement from one another in part emerges from traditional disciplinary/specialist structures, the stickiest and most challenging obstacles to address are largely regarded as relating to knowledge deficits we experience as a result of what we do not know about the normative and cognitive dimensions of other fields [9]. While the different ways in which our lack of insight into other fields manifests itself in the course of cross-disciplinary collaboration is well-documented, where the literature is extremely weak is on the question of what cross-disciplinary knowledge/ cognition researchers need as a means of addressing these issues. There is, for instance, no sustained engagement with which constituent parts of what is unknown, need to be known. So in that sense, while we are clear that there are many things that actors do not know about other domains, we are left no clearer on what aspects of the 'unknown' actually constitutes 'the deficit' that needs addressing; conceivably that deficit might comprise everything that researchers do not know about other fields, or only specific constituent parts of what is 'unknown'. In the absence of that kind of more granular analysis, we have little real sense of the problem, and correspondingly, no foundation for highlighting a potential range of solutions. As we note below, the failure to unpack these cognitive dimensions results in fairly unilluminating and impractical analyses which largely (though not exclusively) consist of recommendations that researchers should 'know more' about other fields. 
Few will disagree with the aspiration for researchers to 'know more' about other fields; however, in the face of an unspecified and potentially infinite range of cross-disciplinary knowledges that could fall into this pedagogical agenda, the recommendation is impossible to operationalise in practice.

In our view, this is largely a symptom of how the cross-disciplinary ideal has been typically been viewed to date-through the lens of 'barriers' and largely abstract approaches to cognitive questions that are far from straightforward. For this reason, the epistemological possibilities of cross-disciplinary knowledge do not come to be evaluated as closely as is needed. To work towards developing a positive analysis and agenda for the kinds of knowledge that might stimulate cross-disciplinary collaboration, consideration needs to be given to two inextricably intertwined queries: firstly, what specific ends 'knowing more' serves, and secondly, what, in substantive terms, needs to be known and for what purpose at different points of the cross-disciplinary collaborative life-cycle. In the absence of that enquiry, what we are left with is an agenda for promoting and enhancing collaborative activity that is largely based on hope.

\section{'Knowing more'}

For those inclined to venture opinions on how to "build bridges' between disciplines, some generally point towards the desirability of 'knowing more' about other fields. This is expressed in a number of ways, for example, of the desirability of researchers developing a broad repertoire of perspectives acquired through interdisciplinary education or from membership in interdisciplinary research groups' ([9], p. 450), acquiring a 'basic understanding of the principles of other disciplines' $[15,21]$, 'learning across disciplines' [58] and of the role that 'encounters' can play, in physically bringing together researchers with 'the aim of learning from, and interacting with each other' ([7], p. 24). Nevertheless, while the notion of learning about other disciplines is repeatedly emphasised, explicitly or implicitly, within the texts of those highlighting the problems that flow from such knowledge deficits, few are willing to specify precisely what needs to be learnt or the level to which it is hoped that individuals develop cross-disciplinary insights. What we are confronted with as a result is a broad and unspecified cognitive spectrum, moving from a complete knowledge deficit, through to basic insight of the 'principles' of other disciplines, potentially up to complete fluency in all fields. Unsurprisingly then, researchers are inclined to locate the problem in cross-disciplinary engagements as consisting of a knowledge deficit, which can be resolved through 'knowing more'. Knowing more, albeit in unspecified quantities, becomes the solution for a range of day-to-day problems in the context of cross-disciplinary obstacles and problems experienced by researchers as they work with specialists from other fields. From researchers in one field being misunderstood by others so that they become an 'appendix' to projects [57], performing 'service roles', e.g. social scientists being asked to 'stuff envelopes' to 'being the general person for anything to do with people' [15], to the overestimation of what one knows or can know about other fields $[49,61,3]$, to the side-lining of conceptual and theoretical contributions different disciplines can make $[49,3]$ the variety of problems that unfold in the 'doing' of cross-disciplinary work as a result of what is 'not known' seems to tantalisingly lead to the conclusion that knowing more about something relating to other fields might be the solution.

At present, however, given the lack of specificity as to what kinds of knowledge the 'knowing more' strategy entails, such an agenda is driven by hope, than practical reality in terms of how to overcome the particular challenges and barriers that researchers confront in cross-disciplinary collaborative efforts. For example, higher education research participants in one study considered that when working in interdisciplinary teams, people would benefit from a basic understanding of the principles of the other disciplines [15]. 'Basic understanding' was represented by the group in four ways: 'Understanding the preoccupations of each member of a team when developing concrete solutions,' 'Understanding the methodological tools available within each discipline' to help build realistic expectations about what different disciplines have the capacity to address, 'Understanding the conversations each discipline is having about the subject being studied', and 'Understanding the professional costs and benefits for team members of doing interdisciplinary research' as it relates to the development of deliverables, publications that promote career development for team members ([15], p. 928). While positioned as items that relate to a 'basic understanding' of other disciplines, closer analysis of each of paints quite a different picture indeed. Instead, each of these items are tantamount to possessing a fairly sophisticated insight of another field: 'Of-Knowledge'. For example, understanding the conversations each discipline is having, or the preoccupations of team members from other fields, might only be achieved through extensive exposure to, immersion in, or advanced integration being achieved with, another discipline. To use one of the example contexts that we alluded to in the introduction, single concepts, such as 'expertise' for example, while seemingly accessible to all, can be underpinned by radically different understandings from field to field [18] so that what counts as an 'expert' or views on how 'expertise' is acquired can be dramatically different indeed. Such concepts are often 'thin' rather than 'thick', so that understanding the meaning of 'expertise' as it is invoked 
within a specific disciplinary domain also demands a prior understanding of how that discipline sees the world, constructs reality as well as an appreciation of which frames of reference are chosen and the operation of different assumptions about the subjects and objects under study, and so on. The issue here is not the desirability of acquiring some 'Of-Knowledge'-for as we highlight later on, researchers frequently do acquire 'Of-Knowledge' as part and parcel of cross-disciplinary collaboration itself; for us, the concern pivots around three interlinked issues which point to the impracticability of an agenda of 'knowing more': (1) the extent to which the process of 'knowing more' is individuated (rather than seen as something that happens during collaborative activity in the form of situated learning); (2) how it lacks epistemic boundaries, in the sense of potentially involving a very extensive and sophisticated understanding of fields that in practice would be impossible to achieve; and (3) how the call for 'knowing more' fails to engage with clear purposes, and in so doing, both exceeds and falls short of what is needed in light of the collaborative bargain itself.

The presence of these challenges becomes far more apparent to scholars who attempt to translate the wish for researchers to 'know more' into a positive theory and practical agenda. Mallaband et al. [49], for example, highlight that while 'comprehension of other subject areas' would be valuable to ensure that members of cross-disciplinary teams worth and value is appreciated, would facilitate stronger communication and support the development of shared understanding and innovative outcomes, the achievement of that level of integration is nevertheless quite a 'challenge' (p. 13). In turn, the often extensive periods of time it can take to achieve the kinds of collaborative skill and cross-disciplinary learning necessary for integrative work is also frequently highlighted as a key challenge [34, 57, 58].

Given the lack of problematisation around cognition, and in particular the lack of specificity around what needs to be known, what we see is a failure to engage with questions of what cross-disciplinary cognition is unachievable-and in contrast, what levels of knowledge are realistic, and desirable. So the interlocking issues we need to start unbundling at this stage include the purposes that addressing cross-disciplinary knowledge deficits facilitate, the extent to which those 'deficits' need to be addressed (how much knowledge) for that purpose (or purposes) and the extent to which strategies to address those ends are realistic and practical given cognitive (and temporal) limits. Attention to each of these issues should help us to work towards articulating a positive account of what researchers might desirably need to 'know' with specific ends in sight, as well as to think through the kinds of contexts and supportive structures that might be put into place to enhance the acquisition of that kind of knowledge. We start here with the collaborative bargain insofar as this factor, above all others, is the most crucially important in helping to define and delimit what researchers need (and do not need) to know about other fields.

\section{Knowledge and the collaborative bargain}

There are some missed opportunities for developing the kind of positive analysis we suggest is now needed. What is apparent from the literature is that few make the critical connection between cross-disciplinary knowledge deficits with the paradigm of collaboration itself. ${ }^{1}$ Potentially, this is the result of the strong focus on the concept of 'interdisciplinarity', which is well-acknowledged for inviting considerable ambiguity in terms of its meaning ([52], p. 14) and can mean 'any form of dialogue or interaction between two or more disciplines'. As such, while scholars and practitioners increasingly point towards 'collaboration' as a desirable activity, some continue to conceptualise cross-disciplinarity in non-collaborative and individualistic ways. As a result, the question of what deficits need to be filled is very often focused on individuals and what individuals need to know about other fields [67]. For this reason, it is perhaps unsurprising that researchers recommend solutions based upon 'Of-Knowledge'.

For the present authors, however, this misses a crucial trick. While acquiring more 'Of-Knowledge', so that one has a more detailed insight into a specific field can surely do no harm, this kind of knowledge proves both insufficient for extra-disciplinary trips into other fields, and equally so, can prove excessive to the needs of a researcher where the specific aim is cross-disciplinary collaboration. Indeed, the questions around cross-disciplinary knowledge deficits directly underpin the critical importance of collaboration (rather than lone interdisciplinary work). Many of us might think of ourselves as seasoned interdisciplinary practitioners who routinely draw from other fields, but in the absence of social immersion within the target field or collaboration with those possessing expert 'know how', we are engaged in an activity where we are in real terms, novices or 'tourists' [61, 68]. Elsewhere, we speak of actors confronting 'glass walls' when they walk unguided into alternative fields; by this we note that our lack of expertise in other fields correspondingly strips us of the meta-cognitive skills to appreciate the extent to which we lack deep understanding about those other fields [61]. For example, when presented with academic papers that report findings in a way that appear understandable to the lay eye, we can underestimate the kinds of disciplinary tools, knowledge architecture and immersion within the expert domain that is needed in order to deeply understand-just as we can underestimate the extent to which 'deep understanding' is wholly inaccessible to us in the 
absence of social immersion in expert domains [61, 68]. What we are inclined to overlook, or forget, is how much of the organisation and identity of a discipline possesses a largely tacit character that is acquired through active and prolonged immersion within the field on the part of its community of practitioners. Even elements of disciplinary knowledge that are made explicit, through monographs, journal articles, working papers and conference presentations, are underpinned by thick layers of tacit knowledge, which in turn, gives meaning to explicit knowledge $[19,60,61]$. That disciplines are constituted in very significant part by such tacit knowledge makes the internal and 'deep' workings of a discipline largely invisible to those outside of it. In this respect, what we might be less inclined to appreciate at a distance is how disciplines 'delimit' units of analysis [15], regulate what constitutes the most important cause and effect relationships' and establish 'a language in terms of concepts, theories and models that represent the phenomena, events and processes that are of particular interest to the discipline' ([9], p. 449). Just as individuals outside of our own field will lack 'deep understanding' of our domain of expertise, so that it is evident to us (in a range of ways) how reading a single paper or even series of them will fail to provide a sufficient gateway into our field, so too will our insight and appreciation of other fields be limited by the same factors. It takes us, as recognised experts within our own fields, a long time to acquire relevant knowledge and know-how, through prolonged immersion in our expert community, so that we should readily expect that others will confront substantial barriers to understanding our fields.

Recognition of this problem, and the full extent of the barriers presenting aspiring cross-disciplinary practitioners, should serve to encourage a different kind of analysis that is currently lacking within the field of interdisciplinary studies. It should, in turn, serve to elevate the status of collaboration as the primary method for achieving the cross-disciplinary/interdisciplinary ideal. This observation underpins to a higher degree of specification how collaboration with experts from other fields proves to be not only desirable but utterly critical for cross-disciplinary and innovation work. Moreover, the same observation helps to narrow our field of vision when addressing the question of what researchers need to know about other fields, and to what end. The aspiration for cross-disciplinarity is best seen as an inherently collective, social and co-operative ideal, rather than an individual one. These observations combined provide a useful starting point for thinking about what we do not need to know, what we cannot know and stake out a different foundational analysis for evaluating the kinds of knowledge we need as individuals to stimulate cross-disciplinary collaborative work.

\section{Identifying individual cognitive limits}

Are there limits to what we can expect individual researchers to know about other fields? Are there limits to what we ought to want researchers to know about other fields? These are two separate questions but they neatly link so as to highlight that the ambition for researchers to know more about other fields must admit of a lower level of knowledge than some suggest would be desirable or necessary. We can, for instance, rule out aspirations for researchers to become experts across some or many (or even all) other fields. Instead, we seek to enable researchers from different fields to connect so that they can start working together and apply their own expert knowledge to bear upon a project in complementary and intersecting ways. This follows from our earlier observations that a collaborative paradigm should be seen as a primary method for achieving interdisciplinarity, and is strongly preferable to lone researchers undertaking extra-disciplinary research as one conceivable way of drawing 'insights' from other fields to inform their own work. The conclusion that we do not need to aim towards transforming academics into experts in other fields-and that we cannot do so-is an important one. Even if some kind of dual expert status were achievable in particular cases, there are three major and interlocking counterarguments to this as an aspiration.

The first, and most significant, is that it is an unrealistic aspiration; the acquisition of expertise in one field alone requires lengthy and intensive social immersion within the relevant community of expertise [19], so that few individuals will have the time or ability to achieve this in more than one field. In cases where gaining expertise in another field is sought, if this involves withdrawal from one's home discipline, we could expect to see a decline in expertise within the home discipline as a result. Even developing very basic insight into other fields can involve a very heavy time commitment. While Knapp et al. [34] highlight the importance of learning the language of another field in order to understand one's collaborative partners, they also recognise that 'from classification schemes and methods to journals and research philosophy, it can be hard enough keeping up with developments in your own field, let alone others'. The second is that talking of individuals gaining 'expertise' in dual fields, or even a very high level of insight in a non-home discipline, misses the point of cross-disciplinary collaborative work. Supposing it were even possible to simultaneously master more than one field (and even the possibility of mastery within a single field is doubtful, unless one is talking about a sub-specialism within $\mathrm{it}^{2}$ ), this unlikely breadth and depth of expertises would actually point against the need for cross-disciplinary collaboration. Rather, the value of cross-disciplinary collaboration lies in its acknowledgement 
of our human cognitive limits-and how it enables us to address our inevitable knowledge deficits in respect of other fields. As Buanes and Jentoft note, our inability to possess unlimited knowledge across a range of disciplines is compensated "by forming research teams of specialists who are able to fill in knowledge gaps for each other' (2009, p. 451). Collaboration provides us with the resources by which to tap into the expertise of social groups, a co-operative and efficient exercise in sharing knowledge that is possessed by actors from a range of fields. In this sense, we are talking about drawing together knowledge communities in order to build bridges, rather than the achievement of individual mastery of a field or fields. Given the fast-moving and high level of specialisation that now characterises most fields, the ability of one individual to master one, let alone more than one field, is fairly implausible and too cognitively demanding a standard. The third counterargument is that in the context of the cross-disciplinary ideal, mastery of two or more fields is not only too high an expectation, but is correspondingly also too low. Ideally, to be alive to novel and path-breaking collaborative work, rather than following more traditional, tried and tested collaborative pathways, knowing something about many fields, would seem to be greatly preferable to knowing substantial amounts about one or two others.

The simple observation that there are limits in terms of what we can know about other fields, and that the collaborative paradigm is so valuable because it brings together experts with deep knowledge from different fields (rather than requiring individuals to master a range of fields), is incredibly liberating. It is liberating by virtue of diminishing in size the putative "knowledge deficit' that needs tackling. Rather than starting with a deficit that potentially encompasses all that a researcher does not know about other fields-a deficit which is not only impossible to tackle, but one that is unnecessary to tackle given the purpose of collaboration, we can focus our attention on what the deficit in fact consists of and work our way out from there. It is this kind of simple observation that has been lacking-but it provides a critical foundation for us to develop a positive theory of cross-disciplinary knowledge and learning. In the context of facilitating cross-disciplinary collaborations then, we are simply aiming for a kind of knowledge that helps us to connect. That is not to say that this satisfies all that we might hope for or expect from researchers that become part of collaborative teams in terms of the knowledges they acquire-a point that we discuss later on-but that in the first instance, identifying a low threshold of 'connective knowledge' seems critical in order to construct an agenda for stimulating cross-disciplinary collaborations that is achievable and practical.

\section{Envisioning: the importance of connective "about- knowledge"}

As we discuss later on, while the 'Of-Knowledge' that researchers need to enhance their existing cross-disciplinary collaborative work will be acquired through or drawn from the process of working collaboratively with others, we are nevertheless left with one kind of knowledge deficit that has been largely neglected: connective knowledge. Here, we are aiming to address a knowledge deficit which strips researchers of the ability to connect with others across the academy. Given the aspirations of futures research, which centralises problem domains that necessitate 'global/planetary, national, regional, and local collaboration' ([28], p. 34), this point of the collaborative life-cycle strikes us as the most critical and pressing-yet one which is ironically the most neglected in literature around the cognitive challenges entailed in cross-disciplinary collaboration. For us, this connective point, which Martin (Martin M, 2015, Architectural discourse of socio-technical systems, Unpublished) speaks of in the context of 'scoping out' and 'mapping' the horizons of collaborative projects, is by far the most significant. In similar fashion, Pennington also points to the importance of this 'fuzzy front end' as significant for being the point where members co-create a research agenda that is capable of linking across their respective disciplines ([58], p. 68). We argue that many of the problems that scholars in the field of interdisciplinary studies point to around cognition find their roots in a lack of broad 'connective knowledge' which is needed at that 'fuzzy front end'-for these are most keenly exposed at this point of 'envisioning' collaborative projects. As we noted in the second of our contexts at the outset of this piece, if one has limited, or perhaps no insight into an array of particular fields or the kinds of contributions they can potentially make, it is likely that such fields will be miscast in the context of prospective collaborative projects, or more likely, overlooked entirely.

Such concerns are beautifully illustrated by Pedersen, who notes how social science and humanities researchers are frequently excluded from the initial formulation of the research problem that defines the joint project', resulting in less integration between fields, and of those researchers becoming mere appendices to projects ([57], see also, [8]). While this underpins the desirability of drawing in other fields at the earliest point of project design, what the present authors are grappling with is the kind of prior 'know how' that is necessary to achieve that early point of connection. If one has no insight into what, for example, social scientists, legal academics or organisational studies theorists do, or the kinds of problem domains they work on, the likelihood 
of identifying the relevancy of their contributions to prospective projects is vastly reduced. In the absence of a wide-angled lens, and given the substantial transaction costs that can attend collaboration with actors from more 'distant disciplines' ([9], p. 464, [57]), one is potentially more likely to look towards more traditional or well-tried and tested cross-disciplinary collaboration pathways, and fields and sub-specialisms with whom one has more cognitive proximity or indeed, social ties ([42], p. 74). Where the aim is innovative futures research, we need to widen horizons and possibilities beyond the obvious, close-by, familiar, comfortable and tried and tested ([42], p. 74, [40]) - and for that, we need to enable researchers to achieve insight 'beyond current borders and thereby generate novel solutions to complex problems' ([34], p. 1). At the same time, it is also critical to temper our expectations in terms of what researchers can know about other fields. In arriving at a level of cognition that is realistic, achievable and preserves the purpose of cross-disciplinary collaboration, we should not aim too high in what we expect researchers to know about other fields. Once we identify that cross-disciplinary collaboration constitutes the ideal vehicle for addressing much of what might be rationalised as an inevitable Of-knowledge deficit, then our aspiration to address gaps in knowledge look like knowledge of a far humbler kind. ${ }^{3}$ In light of the concerns we have highlighted above, as well as the limited time that researchers have for extra-disciplinary learning, a practical agenda for 'knowing more' should focus on an enabling strategy where less is more.

The kind of connective knowledge that we claim is capable of providing the foundation for extra-disciplinary insight consists of 'About-Knowledge'-a range of fairly simple facts and information about the sorts of problem domains and approaches that populate different fields and specialisms. An excellent example of the kind of rudimentary 'connective knowledge' that we centralise here can be seen from the Making the Case series championed by the Campaign for the Social Sciences [47]. Covering a wide range of topics, from Education to Wellbeing, the aim of the series is to highlight the potential relevance of the social sciences for addressing a range of social problems which cluster within those themes. Rather than aiming at providing depth of insight into the field, each pamphlet highlights in broad brush fashion the kinds of problem domains and questions that have occupied social scientists, the ways they went about their research, the insights that research yielded and the collaborative partnerships they were involved in. In real terms, the Making the Case pamphlets appear to make excellent use of the Research Excellence Framework 'Impact Case' Studies [64], and present examples of impact in a way that is readable and accessible to all. But critically for us, the series is explicitly aimed at providing some insight into a rich and diverse field through a high-level approach. The range of research work profiled, for example, around Sustainability, the Environment and Climate Change, highlights the important and impactful interventions of social scientists working in concert with others, including industry, government agencies and local communities, around biopesticides, flood risk, coastal erosion, fuel efficiency, recycling rates and so on [14]. Take for example an extract showcasing Elizabeth Shove's work,

Interviews with more than 100 households, policyactors and manufacturers, plus historical studies of bathing, laundering, heating and cooling indicate that practices like those of taking a daily shower or of maintaining $22{ }^{\circ} \mathrm{C}$ indoors, whatever the weather, cannot be explained in terms of personal preference or individual choice. Rather, successful energy-consumption reduction is a matter of understanding how patterns of daily life evolve along with ordinary technologies and infrastructures like bathrooms, kitchens, and washing machines. Put simply, people do not use energy; they use the services it makes possible. The researchers found that the issue is one of convention and infrastructure, not of individual choice [14].

Standing in contrast with an 'Of-Knowledge' approach, the kind of insight we acquire is of the potential applications of social sciences to developing stronger understandings of human-technological interaction. In highlighting aspects of the kind of problem domains that social scientists are involved in, and how social science can be operationalised in practice, this series has the strong capacity to challenge narrow or stereotypical perceptions of the kinds of work that social scientists do. While offering a basic insight into what other fields do, it is an approach that works well for shining a light on the social sciences, and one that if adopted in other fields, from specific domains like medicine, to collaborative clusters of activity in futures research, has similarly strong potential for achieving the same outcomes.

The level of 'connective knowledge' we propose here for academics and researchers in higher education shares the same ethos embedded within the Making the Case series. Nevertheless, given our preference for high-level introductions to the work that other fields are engaged in, some may be sceptical of our claim that 'connective knowledge' is 'knowledge' at all. One can argue that we are advocating the delivery of a series of decontextualized 'facts', 'information' [1], 'beermat knowledge' or 'popular understanding' accounts [19] about other fields and disciplines, that in isolation is not an enabling kind of information at all. Nevertheless, importantly, we are not talking about 'facts' in pure isolation. Rather than being regarded as situated at the bottom of the taxonomy of learning and the 'enemy of 
understanding, declarative knowledge, in the form of facts and transmission of information is now increasingly regarded as critical for the achievement of higher order skills (the ability to analyse, compare and evaluate) ([16], p. 17). As Christodoulou emphasises, good analytical approaches depend on a bedrock of facts rather than being amenable to abstract thought alone. To imagine what it would be like to live in a rain-forest, beyond it being rainy', one needs background knowledge to offer more than shallow responses ([16], p. 22).

In the world of higher education, given our target population, declarative knowledge in the form of facts and information about other disciplines takes on far broader significance. This permits researchers to imagine beyond their own field or discipline and to identify the kinds of potential connections that might be made by combining one's own expert knowledge with other fields. To achieve these connections, some basic level of insight into the kinds of contributions other fields can make seems both critical and necessary. What we are proposing advocates a model of cross-disciplinary learning where researchers start to develop a 'T-shaped combination of skills. ${ }^{4}$ Those possessing this combination of skills are described as being,

$[\mathrm{N}]$ ot only experts in specific technical areas but also intimately acquainted with the potential systemic impact of their particular tasks. On the one hand, they have a deep knowledge of a discipline like ceramic materials engineering, represented by the vertical stroke of the T. On the other hand, these ceramic specialists also know how their discipline interacts with others, such as polymer processing - the T's horizontal top stroke [31].

This is not to claim that it is critical for researchers to acquire intimate knowledge of how their field 'interacts with others', but simply that some cognitive foundations that set into motion the possibility of making connections with other fields would be worth setting down. As Boh et al. highlight,

[I]ndividuals build both breadth and depth of expertise by anchoring themselves in one or a few core technical domain areas, and understanding how their core domain expertise area interacts with other disciplines. Thus individuals learn to recombine existing components in novel ways while simultaneously building up new connections and new cognitive nodes of knowledge. Once an individual builds up a rich repertoire of knowledge components and also constructs a dense scaffolding of strengthened links between existing knowledge components and new knowledge components, he or she can more easily integrate new knowledge components into a large web of existing knowledge components ([5], p. 356).

Our proposal then advocates a model of cross-disciplinary learning which, while pushing in the direction of acquiring 'T-shaped combination of skills', will more often fall far short of the 'dense scaffolding' that Boh et al. [5] point to. Rather, it provides the preparatory foundation for connections to be identified as possibilities and acted upon. What transforms a series of isolated 'facts' and 'information' into something else-notably connective knowledge-is how they combine with the researcher's own deep expertise in their home domain and enable her to make the critical links between her specialism and others.

Our privileging of 'connective About-knowledge', while centralising the kinds of practical concerns we have highlighted above, also becomes critically important by virtue of what has tended to be missed from the interdisciplinary literature: how we form connections between researchers and other domains of expertise. When this aim is made central, the kind of knowledge deficit that are dealing with looks far narrower and manageable. As a result, rather than needing to make recommendations that researchers need to 'know more'-an 'Of-Knowledge' involving highly technical understandings of another field or fields-we can instead focus on the kinds of knowledge that could prove crucial to support 'envisioning'. Profoundly wrapped up with the making of connections across a wide terrain, the process of envisioning is where actors 'scope out' specialisms and map collaborative horizons and conceptualise the 'possibilities and the selection of objectives and priorities' (Martin M, 2015, Architectural discourse of socio-technical systems, Unpublished). The kind of knowledge we highlight as critical constitutes the most fundamental sort-a kind of basic 'About-knowledge' around the kinds and types of problem domains and concerns a field or specialism is engaged in, in order to enhance researchers' basic 'know how' about what other fields do in the crudest of terms. Under our rationalisation, if a researcher suffers from a knowledge deficit about what kinds of basic concerns and approaches drive multiple fields, those fields are unlikely to make it onto that researcher's 'research radar' at the point of designing projects that in principle could spur innovative collaborative research. As such, basic knowledge of at least some of the problem domains and approaches which populate multiple fields will extend the possibilities for how researchers imagine a project's horizons, and impact upon which specialisms are prospected for collaborative partnership.

That connective 'About-Knowledge', rather than more sophisticated forms of extra-disciplinary 'Of-Knowledge', might be more valuable for stimulating cross-disciplinary 
collaborative connections also finds support from other quarters. There is now a developing body of work that highlight fundamental misconceptions and stereotypical ideas about what researchers within non-home fields actually do [62] in ways that lead researchers to erroneously overlook and exclude particular domains for cross-disciplinary projects [2, 49, 3]. Addressing basic misconceptions about fields and specialisms-for example, that legal academics researchers are typically involved in 'litigating cases' [62], or wholly non-specified ideas about social science so that social scientists are seen as the 'people people' [49] — do not require much 'corrective' information beyond highlighting the richer range of research problem domains in which those disciplines are engaged, and the potential contributions that those fields can make to cross-disciplinary collaborations. The second source of support comes from a new and promising body of work around the concept of 'serendipity'. While commonly associated with unexpected fortuitous events [4], such as chance scientific discoveries to stumbling over a valuable source of literature whilst looking for another [48], the role of pure 'chance' is increasingly downplayed within the literature. As McCay-Peet and Toms note, no factor 'is more strongly associated with serendipity than the "prepared mind"' ([51], p. 1465). In this respect, one's prior knowledge and experience plays a critical role in priming individuals to recognise a 'trigger' relative to their work ([51], p. 1472). As such, while serendipitous events can play a role in stimulating ideas and discovery, they do not operate in a vacuum-rather identification of, or appreciation of a serendipitous connection or finding is contingent, and operates in interaction with the individual, her environment and state of mind. But critically, and strongly aligning with the concept of 'envisioning' we highlighted earlier, 'without the prepared mind there would be no connections to make' ([51], p. 1474). The final and perhaps most significant source of support comes from analysis of the literature around what we can call 'human enablers' in the context of cross-disciplinary collaboration and innovation. At a very general level, these human enablers are variously referred to as 'knowledge activists' [36], brokers [10, 69] or boundary spanners [41]. While each of these labels admits of different though cross-cutting roles and attributes, there are a variety of qualities that bind them together. Often conceptualised as 'special' people embedded within networks who play a key role in bringing 'unlikely partners together, in breaking through red tape, and seeing things in a different way' (LGMB cited in [70], p. 109), these human enablers cross organisational and/or cultural boundaries in order to exchange knowledge or mediate interactions [45]. Evidently regarded as possessing strong skills in coupling problems, the cognitive styles of the boundary spanner that are most frequently emphasised are the ability to 'think laterally', take a 'holistic view' or see 'the big picture'. While the literature demonstrates a strong preoccupation with the boundary spanner's personality, disposition, interpersonal skills, among other social attributes, the assessment of the particular technical cognitive attributes of boundary spanners is our focus here. While some emphasise the desirability of a boundary spanner possessing depth of knowledge in one area, more frequently boundary spanners are emphasised as 'generalists' [66] and 'a jack of all trades and master of none' ([70], p. 119, [53, 66]). Also implying an absence of cognitive depth, boundary spanners are emphasised as being seen as legitimate members' of both of the served communities while still remaining peripheral to them, as full participation on either side usually impedes effective boundary spanning ([39]). In this respect, the boundary spanner is characteristically similar to those possessing 'T-shaped combination of skills'.

While the focus of the literature tends to be on the special enabling role that boundary spanners can play within organisations and institutional settings, it also opens up far broader possibilities when we consider the current problem domain. Undoubtedly, some may be more skilled in connective work, or possess the kind of dispositions or charisma that helps to stimulate the formation of connections across domains; nevertheless, in light of the emphasis on these brokers as 'functional generalists', it also raises interesting questions about how we might try to enhance the connective capabilities of all researchers. That is our aim here. Where the aspiration is to achieve 'About-Knowledge' of this general sort, it would be surprising if this did not help to enhance the connective abilities and collaborative foresight of all researchers. In other fields, including medicine, such ideas are being tested and operationalised-albeit to a degree and scope that extends far beyond what we propose. Repeated emphasis on the importance of broad-based training (BBT) in order to equip doctors to respond better to the changing needs of patients and the service generally was followed with pilots in England in 2013 and rolled out in many regions by 2016 [53]. In follow up interviews with trainees that had been part of the postgraduate BBT programme, trainees described how BBT had enabled them to become 'more holistic practitioners', 'to better understand the patient journey through the healthcare system', to better understand the 'pressures and limitations experienced by colleagues in different specialties' and to become 'better doctors' [53]. As the authors of the study highlight,

Those in a generalist role might helpfully be thought of as boundary spanners-doctors who reach across 'structural holes' to aid the flow of knowledge about a patient's care between previously poorly connected 
disciplines. Boundary spanners can play an increasingly important role in the healthcare setting, addressing the challenge of silo working and professional tribalism [53].

A good deal of the literature in this area also highlights draw backs for the boundary spanner in a range of contexts. Having strong parallels with negative experiences expressed by those in the higher education context engaged in interdisciplinary work [38], one of the main concerns related to being the 'jack-of-all-trades' - a generalist-as distinct from the rest of the field [35]. This was particularly prevalent in the context of the clinical domain, with those trained as generalists, feeling isolated, different, misunderstood, like the 'black sheep' and a lack of belonging ([53], pp. 4-5). Nevertheless, as we discuss next in evaluating the 'how to' of the dissemination and acquisition of Connective About-Knowledge, what we propose here differs from the kinds of approaches suggested to date in important ways.

\section{The lost generations: acquiring connective about- knowledge}

Over the last few decades, we have seen a significant upward spike in activities designed to enhance interdisciplinary capacity and learning across borders and boundaries. There is now a vast number of 'interdisciplinary' training initiatives aimed at undergraduates and postgraduates in the form of discrete modules or even entire programmes [17], as well as a proliferation of units which are specifically interdisciplinary in orientation. Moreover, such initiatives have been 'trickling up', with a large number of events and training initiatives that target early career populations within and outside of academia [22]. Such programmes are often explicit in seeking to socialise new populations into an approach to research and practice where crossing boundaries and sectors is the norm. In similar force, masters' programmes which are aimed at drawing together multiple fields, such as social science research masters, express similar aims. The theory behind such targeted approaches seems to be that,

Starting as early as possible for lifelong learning seems to be one of the keys to successful interdisciplinary education and work. Once ingrained in a certain discipline it will be hard to lower the disciplinary egocentrism [33].

Nevertheless, despite fairly heavy investment in such initiatives on the part of many higher educational institutions, the exclusion of the vast majority of higher education staff and researchers from these has barely been noticed. In light of the fact that the bulk of research, innovation and engagement work will be currently undertaken by this excluded population, the absence of focus on the wider population as a whole reveals a startling lacuna, and indeed, potentially a vast number of missed opportunities for innovative and path-breaking cross-disciplinary collaborative work. As Larson et al note, 'much has been written about facilitators and barriers of interdisciplinary research' but 'the need for didactic training of faculty is rarely mentioned' [37]. ${ }^{5}$ Very often the focus on generating capacity is upon creating a 'new generation' of researchers (see for example [27], p. 46) who are socialised into a different way of thinking, rather than consideration of the significant opportunities that could flow from addressing a far wider audience. To a significant degree, one of the reasons for this might stem from the assumption that a gap in knowledge needs to be addressed, more often than not, through formal training programmes. Grappling with the gap in cross-disciplinary training, Larson et al make such a recommendation and argue that,

Although universities may be poised for interdisciplinary research, strategies for faculty preparation and support are sorely needed. Reducing institutional structural and cultural barriers is necessary but not sufficient to move collaborative research forward. What is needed now are specific tactics and action plans to prepare faculty for what is, for some of them at least, a new way of working and thinking ([37], p. 41).

While Larson et al.'s proposal consists of a 'didactic course' designed to 'build on core competencies preparatory for building and sustaining interdisciplinary research models' ([37], p. 41), what we propose looks quite different. Our aim is not to transform academic researchers into pure generalists (or for that matter, boundary spanners, or fully-fledged interdisciplinarians)-particularly given how depth of knowledge within one's own domain of expertise constitutes the beating heart of the cross-disciplinary collaborative paradigm. We would not, of course, discourage higher education institutions delivering programmes around cross-disciplinary collaboration and research methods that specifically target all researchers, but we are cognisant of the considerable cost such programmes entail for institutions, and indeed, of the considerable time investments these would entail for academic staff.

Critically, and irrespective of the availability of such 'didactic courses', providing opportunities for researchers to acquire 'About-Knowledge' does not necessitate programmes of that kind. Instead by virtue of centralising a far lower level of knowledge, this admits of far simpler, shorter and cheaper modes of delivery and acquisition. 
What we are proposing is a far lower-level and rudimentary knowledge about the kinds of work and approaches that populate a range of academic fields and specialisms. We seek to provide a range of learning opportunities that offer useful glimpses across the academic landscape, and provide windows of possibilities for prospective collaborative work that might otherwise be missed.

In this respect, a series of cross-disciplinary events, aimed largely (though not exclusively) at researchers within higher education, comprising roundtable panels of experts from a field that are explicitly geared at talking about why their field 'matters', and giving examples of the kinds of work and approaches that populate it, would prove more than sufficient for these purposes. This requires a simple re-think or extension of the target audiences that fall under the heading of 'public engagement' so that academic researchers are also centrally in mind. At present, there is good reason for thinking that academic researchers are not the 'target' audience (although there are questions in the field of public engagement as to whether sufficient thought is being given to the question of audience at all). While myriad 'public engagement' events are directed towards laypersons, including industry actors, showcasing for example, the relevancy of the 'social sciences' to industry (see [32]) or other external prospective partners (see for example, the launch events that have attended the Making the Case series, [13]), very typically the imagined 'publics' at the core of public engagement events appear to be largely regarded as a form of 'outreach' [23] to the 'general public'-external to-rather than within-the university walls. ${ }^{6}$ Reflecting the concerns of Lewis and Watermeyer [44] that 'the point of public engagement isn't always clear' and of the status of public engagement events as being regarded as a 'discrete and fringe activity', in practice, our argument makes a strong case for increased value of these events, and for affording them significantly more status within universities as a form of 'connective' education for researchers. While in practice, academic researchers are likely to attend a variety of public engagement events [43] which can serve to extend our insight about what other fields do, for the present authors, the public engagement model as currently pitched largely to external actors could stand as a critically important vehicle for enhancing connectivity across academia. As will be apparent from what we have highlighted above, most academics whilst developing specialist expertise in a field, will nevertheless be as much a member of the 'general public' or the 'laity' in respect of other fields. For this reason, engaging 'publics' within the higher education sphere who lack insight into other expert fields and domains is also critical. A little knowledge about a field can go a long way. Rather than attempting to deliver upfront the kinds of 'Of Knowledge' that some have argued would enable the would-be cross-disciplinary collaborator to be better prepared for navigating those kinds of encounters (a challenge that we believe is largely impossible in any event), critically, our emphasis here is upon opening doors and widening collaborative possibilities.

\section{Beyond connection: acquiring of-knowledge through collaborative interaction}

Let us try to convince you, nonetheless, through the labour of our collaborations - as a human geographer and sociologist - with many others from multiple disciplines - that there are forms of interdisciplinary practice that, even if only occasionally, even if sometimes fractious, even if freighted with all the worries and anxieties that we are going to set out below, even if they sometimes fall apart, are still sometimes epistemologically and interpersonally exciting ([11], p. 14).

Some may be highly sceptical of our recommendation that a low threshold of cross-disciplinary 'About-Knowledge' is afforded priority as a strategy for initiating interdisciplinary collaboration. Such a suggestion may seem to be unambitious and simply point towards a form of cognition that is far too low. The kinds of clashes, confusion and misunderstandings that can occur between researchers from multiple fields will not, some will argue, be addressed by the kind of basic cognition that we point to. While our aim is not to resolve or address all of these problems, but rather to identify the lowest level of cognition about other fields to mobilise our connective capital-we would also argue that the problems that researchers encounter through epistemic clashes and so on in cross-disciplinary collaborative work, will not be overcome through the delivery of prior, and explicit Of-Knowledge either.

To a very significant degree, the kinds of broader problems that researchers encounter in the context of developing cross-disciplinary collaborations, including the 'often challenging day-to-day realities that people from all disciplinary backgrounds experience when they live 'between' disciplines' ([11], p. 5), seem to be largely inescapable. Indeed, it may be that the confrontation with differences between fields, specialisms and disciplines, particularly at the 'fuzzy front end' of research agendas ([58], p. 68), is a necessary and critical part of learning how to become a good cross-disciplinary collaborative researcher [69]. In turn, much of the work of learning 'what one needs to know' about other areas in order to work with specialists from other fields will necessarily be learnt on the job-through interaction-and across a lengthy period of time. While we highlighted 
earlier laments on the part of scholars about others placing them in a purely service role-or as an appendix or token to a project [8,57], Knapp et al. [34] highlight how the service role itself can be used to build strong future collaborative relationships,

Service work is often an excellent way to establish a collaboration, get the partners to trust in your ability and expertise, and learn enough about other disciplines to start making direct contributions, whilst at the same time, co-authoring high quality publications. Service work will show that you take the collaboration seriously and help you to establish a reputation as a reliable and analytically keen scientist... ([34], p. 5).

By virtue of the sometimes messy and 'entangled' experiences that researchers report experiencing in working across disciplines (see for example, [12]), and the wide variety of challenges that researchers can confront [50], it is hard to imagine any particular kind of knowledge that could be delivered upfront to enable researchers to avoid these multitudinous problems. In light of these, the call for researchers to 'know more' about other fields looks incredibly naïve. No amount of 'knowing more' would be enough. The attempt to explicate 'more knowledge' around the languages, sub-cultures, expectations, reward models and so on, relating to other fields (and surely one would have to be selective about which fields given constraints of time alone) assumes that we can actually make explicit the deep experiential knowledge that regulates fields-or prepare interdisciplinarians and futures scholars in particular, for the relational, socio-emotional and affective challenges which surely await them as they set about negotiating the meeting point between different fields. This is not to diminish the importance of didactic forms of cross-disciplinary training, but to deflate our expectations of what that training can deliver. Much of what we know and need to know comes with the pains and pleasures of experience, and through the acquisition of a great deal of Of-Knowledge that is of a tacit and experiential nature. Similar emphasis is placed on the critical role that action research, dialogue and participatory approaches play in futures research, and of the importance of 'context-specific understanding, based on diverse experiences' and of an ongoing 'relational process of dialogue across diversities, where holisms can emerge as aspects of our ongoing journeys'[63]). These are not pre-packaged knowledges, but ones which are dialogically innovated and discovered. For all these reasons, our aim cannot be to advocate a knowledge 'delivery' programme that promises to remove the challenges which the present authors believe are part and parcel of an immersive 'social' journey.
Instead, our aim has been to think about where it can be said that a cognitive deficit exists that in principle is amenable to a targeted strategy. It is in this respect that we have highlighted 'About-Knowledge', the kind of 'basic' knowledge that better assists us to connect, to have a sense of what is out there, to imagine and envision the possibilities and intersecting problems that researchers from other fields are working on. It is this kind of basic knowledge that opens out the possibilities and widens a researcher's horizons at the point of evaluating the kind of expertises that could make a useful contribution to a project's future. Even then, this more modest corpus of knowledge that we have centralised here will still require an investment of time, rather than presenting a store of knowledge that can be delivered at one time to prospective researchers.

Beyond this, there is no format that we can think of that will deliver 'knowledge' to researchers that can come even close to the kinds of experiential knowledge that one acquires through cross-disciplinary collaboration. In this latter respect, the 'doing' and performing of cross-disciplinary collaborative work points to a far longer journey-one that will occur across an extensive period of time, and capture a wide range of knowledges that are acquired of quite different sorts, including the totally unexpected. While there is still a limited amount of work exploring the experiences of researchers engaged in cross-disciplinary collaboration [12], the factors now being centralised increasingly emphasise the significant time investments entailed [8,29]. Highlighting the length of time it can take to establish an integrated knowledge field, Pedersen, for example, notes how 'designing research policy for interdisciplinary collaboration requires a long-term perspective and a broader notion of integration than is usually adopted' [57]. In similar force, others point to the impact of collaboration, on their individual research agendas, 'slowing down my usual rate of publication by dint of spending time developing strange collaborative research with researchers who need explanations of some of the key concepts and methods in my field' ([11], p. 12). Those like Conley and Fisher [20] discuss their ongoing engagement as social scientists with natural scientists to reflect on the broader dynamics of scientific research. The authors note the 'despair' of wondering if a 'real understanding' of what researchers in a different field did in their daily practices would ever emerge, the time spent in the laboratory for establishing 'rapport and trust relationships' and the critical importance of 'material engagement' (hands on) in the lab and of being an 'embedded social scientist'. Rather than conceptualised as a 'sporadic interdisciplinary collaboration', this was a process, one where the researcher is developing a kind of 'interactional competence' in an alternative field, 'honing' a suite of abilities 
around developing a collaborative disposition and moving between micro and macro contexts. Indeed, for Conley and Fisher, interactional competence involves hands on work, and the development of particular dispositions including the capacity for humility, an ability to admit ignorance and to ask questions, to empathise with and step into the shoes of one's collaborator (see also, [8]).

That the vast majority of what we need to know is likely to be developed 'on the job' and across time is emphasised in much of the more practically orientated interdisciplinary literature. Some also emphasise the gradual acquisition of cross-disciplinary knowledge through activities and engagements that draw researchers into extra-disciplinary communities. In this regard, Buanes and Jentoft note that interdisciplinary research necessitates a 'broad repertoire of perspectives acquired through interdisciplinary education or from membership in interdisciplinary research groups' [9]. Perhaps offering one of the most sophisticated engagements around the temporal dimensions of cross-disciplinarity, they also argue that while structural obstacles to cross-disciplinarity can in principle be speedily addressed, the normative and cognitive barriers cannot. In this respect, they note that, 'One can prepare the ground for an interdisciplinary culture to emerge, but it typically develops as a by-effect of other initiatives' ([9], p. 453). In this respect, they emphasise at a variety of junctures, a strong sensitivity to time-one that portrays interdisciplinary learning as journey, where the interdisciplinarian learns and adjusts her perspectives along the way. This kind of approach points towards a more realistic agenda of cross-disciplinary knowledge acquisition, in no small measure because it is premised on a gradual acquisition of knowledge that is feasible and increasingly part of what academics already do [49]. Even for serendipity scholars, the role of time plays a key role in discovery, where feeling overwhelmed by information can result in key triggers being missed or overlooked [51]. Indeed, for others, who emphasise the variety of barriers (cognitive, normative and structural) confronting scholars prospectively working towards interdisciplinary collaboration there is a similar focus on this a continuing process, one that necessitates time to foster relationships and collaboratively learn with others [29]. In this respect, some emphasise the importance of providing opportunities for researchers from different disciplines to come together in the form of 'encounters'. Such encounters have the aim of promoting 'open communication across researchers from different fields'. While such open encounters provide a setting for 'listening to, being curious of, and understanding each other's perspectives and potential contributions to joint efforts', a form of 'appreciative inquiry', the emphasis is on creating the conditions where 'interactions can be fostered between researchers' ([7], p. 24).
What is important in terms of work that centralises the temporal dimension of interdisciplinary learning is that it positions 'knowing more' as a process that occurs across a far longer period of time, and as a form of knowledge or knowledges that are acquired with increasing interaction with scholars from different fields. Of course for those that seek out quicker solutions for addressing the variety of epistemological, normative and cognitive clashes that arise from a lack of appreciation for, or about different fields, the conclusion that these clashes themselves might be an inevitable part of collaborative work, and part and parcel of a long-haul journey, might be an unwelcome one. Nevertheless, for the present authors, it is a valuable and intrinsic part of the cross-disciplinary collaborative process. For this reason, centralising a more humble form of know how in the form of 'About-Knowledge', a connective knowledge, constitutes the strongest and most feasible starting point for embarking upon that journey.

\section{Conclusion}

In the context of the wide and varied calls for cross-disciplinary collaborative work, the critical importance of collaboration to the vibrant and integrative work of futures research, and the now voluminous literature that highlights the range of challenges, pitfalls and perils inherent in that kind of work, we have identified a significant gap in the literature. In particular, there has been a lack of attention paid to the factors and competences that drive and stimulate the initiation of cross-disciplinary and sectoral collaborative work. While the present authors centralise the critical role that greater insight into other fields might play in helping to enhance connections between researchers situated in different and perhaps distant domains, we also note the lack of detailed engagement with the question of what researchers need to know about other fields in order to collaborate effectively across different fields. In respect of those that have focused on this dilemma, while scholars have provided extensive and useful coverage around the variety of ways a lack of insight into other fields creates problems for collaborative teams in the course of cross-disciplinary work, where that scholarship is currently weak, is in the furnishing of solutions. At present, and sticking closely to observations of how knowledge deficits constitute a barrier to cross-disciplinary collaboration, the elixir is vaguely located in aspirations for actors to 'know more' than they currently do about other fields, and that this greater knowledge somehow constitutes the gateway to interdisciplinary work and cross-disciplinary collaboration. As we have argued, this approach is problematic for a range of reasons. In the absence of pointing to specific constituent elements of what is unknown, that needs knowing, we 
lack the ability to identify what the 'deficit' is, and how to address it. As a result, we are left none the wiser as to what knowing more about other fields will help prospective collaborators to achieve-or indeed, 'what' and 'how much' actors ought to know about other fields for that purpose. For this reason, it is impossible to construct meaningful strategies to inform policy and practice.

Our aim in this piece has been to develop a positive agenda for addressing the kind of extra-disciplinary knowledge that might help to stimulate, enhance and initiate cross-disciplinary collaboration. For this reason, we sought to disentangle the variety of ingredients around cross-disciplinary collaboration in unpacking the purposes that 'knowing more' about other fields might serve, as well as fleshing out more practical elements, including what it is that we need researchers to know and can realistically expect researchers to learn about other fields. Here, we drew a distinction between 'Of-Knowledge' and 'About-Knowledge' in respect of other fields, in order to conceptualise the different kinds of knowing that might prove necessary at different points of the collaborative life-cycle. In response to claims that individual researchers should 'know more' field-specific knowledge to enhance collaborative work, we highlighted a range of concerns in respect of a level of cognition that is far too demanding in practice. We also noted how such 'knowing more' advocacy often ignores the critical role that cross-disciplinary collaboration ought to play in the sharing of expertise across a collaborative team and the inevitable learning about other fields of the 'Of-Knowledge' kind that field actors will acquire the life courses of collaborative projects. For this reason, we argued that 'Of-Knowledge' cognitive deficits are best addressed as part of the collaborative bargain itself. This is not to claim that the acquisition of elements of 'Of-Knowledge' is itself problematic-instead, our concern lies with the claim that researchers ought to acquire knowledge of this kind and that this will enhance cross-disciplinary collaboration. It is not clear, to us at least, how didactic approaches to skill researchers up with more granular field-specific insights-in the form of 'Of-Knowledge'could ever be viable given that these approaches require very extensive knowledges in respect of a specific field. In turn, as we argue, the very reason for collaborating with actors from multiple disciplines is by virtue of their expertise in that field-a form of 'Of-Knowledge' that cannot be acquired to that level of sophistication without extensive immersion and interaction within the field in question. This point is critical. What proponents of 'Of-Knowledge' are advocating is the acquisition of field-specific knowledge that will inevitably be vastly inferior to the knowledge and deep understanding that experts within the target domain actually possess (see further, [61]).
Nevertheless, as we highlight, with our eyes on the prize - the desirability of enhancing researchers' awareness of other fields and of mobilising prospective cross-disciplinary collaborations - there is one kind of 'knowledge deficit' that in principle can be tackledthough of a very basic kind: 'About-Knowledge'. Consisting of a rudimentary form of facts and information about other fields, incorporating a range of example problem domains and approaches that populate different fields and disciplines, we highlighted the important role that 'About-Knowledge' plays in its ability to create awareness of potential connections. Connective knowledge in this sense is not knowledge of connections, but the kind of knowledge that makes connections possible; in turn, what makes 'connective knowledge', knowledge, is in the ability to make associations between one's own expert specialism and other fields, to identify connections and mobilise them between disciplines.

That one possesses connective knowledge of this sort, of course, is no guarantee that such connections will be made, or that if made, that they will be successful. As we highlighted earlier, there is a great deal of learning that occurs after the point of connection through interaction with other actors. In the context of futures research, myriad opportunities exist to act as critical springboards for situated learning of precisely this sort, including the European Foresight Program which is aimed at developing a global network binding together different communities and professionals [25]. For the present authors, such collaborative networks and partnerships provide opportunities for ongoing learning and dialogue that are non-substitutable. Yet, while we have treated as distinct different points of the collaborative life-cycle throughout this piece, notably distinguishing between cross-disciplinary collaborative engagement in progress, and the point of 'envisioning' as a prior point, it is worth our noting here that some forms of collaborative engagement can operate to blur that distinction in practice. In particular, it may be here that futures studies could play a powerful role in defying these boundaries. Innovative design inquiry initiatives, aimed at bridging 'scientific understanding and community-based knowledge' to reflect on 'day-to-day realities and possible futures' ([24], p. 57), as well as the increasing use of Living Labs for co-production and knowledge transfer work [55], provide unique participatory, problem/scenario-based, dialogical and transdisciplinary modes of engagement that could have extraordinary connective potential. To the extent to which futures studies initiatives render visible the range of human-technological contributions and sources that inform its work, these strike us as having unparalleled potential for enhancing 'About Knowledge'. But this point about the visibility of sources of expertise is critical. In this sense, 'About Knowledge' is firmly about understanding where expertise lies (whether academics, organisational 
actors or actors within communities) and providing accessible examples of how different kinds of expertise play out in active, practical settings (as opposed to more granular field-specific 'Of-Knowledge'). It is this step-seeing how expertise is enacted in different situations that present opportunities for understanding the role that different fields, specialisms, networks and actors could potentially make-that enables broader connections to be made. In this respect, the orientation of futures studies itself and the broad range of local and global challenges that it encompasses could serve to situate the field as a potentially important platform within and outside of higher education for the acquisition of 'About-Knowledge' and in turn, it maybe that the field provides an important method for how we unleash our connective capital.

In arguing for a more rudimentary approach in respect of what researchers need to know, we drew support from three distinct areas to highlight the potential operation and benefits of such an approach. We highlighted how even a little insight about other fields could help extend individuals' ideas about the role that other fields can play in their own work-and help address misconceptions or non-conceptions that might otherwise lead to those fields being erroneously overlooked or excluded. We also noted that even in the context of serendipity, which in particular contexts may serve to bind individuals together as collaborative partners, that serendipity is not regarded as a pure chance event divorced from what individuals know, or their broader environment. As such, the possession of a basic insight into what other disciplines do may help to provide the foundation for the 'prepared mind'-the kind of mindset that seems to typify the skills and attributes of 'T-shaped' actors who possess depth of expertise in an area, as well as a strong ability to identify connections between their field and others. And finally, we noted the low cognitive threshold of cross-field/disciplinary cognition that boundary spanners draw upon in order to form connections across fields and domains. While in the future technology is likely to play a stronger role in helping to enable the identification of innovative and path-breaking connections $([55,59])$, and more immersive and problem-centred ways of drawing researchers together could enhance our cross-disciplinary competence $[6,26]$, it is difficult to conceive of a point in time when the 'prepared mind' will not still prove critical for the prospective interdisciplinary collaborator. And in this regard, where researchers know a little more about the relevance of other fields across the academic terrain, that knowledge is likely to go a long way.

\section{Endnotes}

${ }^{1}$ Although we acknowledge that there is still an important role that lone interdisciplinary scholars can play, we note that cross-disciplinary collaboration provides an unparalleled form of cross-disciplinary engagement, and that this mode of engagement is critical for robust policy-orientated work [61].

${ }^{2}$ Moreover, it may be that even in intra-disciplinary contexts, we fetishize and inflate the expertise that we possess as individuals. In this respect, expertise is a property of a social groups rather than individuals [19], and for all of us engaged within academic work within particular fields, we can readily appreciate the limits of our ability to sum up our 'field' as a whole [9].

${ }^{3}$ The focus on a more basic level of knowledge, as we discuss slightly later, has significant benefits when evaluating how to address the needs of a series of 'lost generations' within higher education institutions, who have been missed from initiatives designed to provide a grounding in cross-disciplinary knowledges and approaches.

${ }^{4}$ Our thanks to Mike Gorman who introduced us to this concept in his recent presentation at SEESHOP 2018, the Studies of Expertise and Experience Annual Meeting, Cardiff University.

${ }^{5}$ Larson et al. [37] also note that even comprehensive reports [54] evaluating how to increase and enhance interdisciplinary capacity within higher education also fail to make any mention of the need for training in respect of faculty members. The neglect of faculty above early career stage (or entirely) is also apparent in other areas. In the context of socio-legal studies, similar concerns were highlighted about a skills gap in relation to empirical research methods among faculty members, nevertheless, the recommendation in terms of how to address these 'shortcomings' focused on training for 'undergraduate, postgraduate, and/or the postdoctoral level' ([27], p. 53).

${ }^{6}$ For example, 'Public engagement describes the many ways in which higher education institutions and their staff and students can connect and share their work with the public' (cited in [23], p. 726).

\section{Acknowledgements \\ We are grateful to the British Academy for providing us with the financial support to undertake this work. This paper presents theoretical work relating to our broader empirical project, 'Multidisciplinary Understandings of Legal Academia'. In addition, we wish to thank Professor Harry Collins, Professor Rob Evans and Professor Adam Hedgecoe (Centre for the Study of Knowledge, Expertise, Science, Cardiff School of Social Sciences, Cardiff University), and the broader Studies of Expertise and Experience research community. The work we present here is the result of their input and support over the years. Finally, our thanks to the editor and the anonymous reviewers of this piece for their thought-provoking and insightful comments.}

\section{Funding}

Support for this work has been provided by a British Academy Small Grant (Grant number 509225).

\section{Availability of data and materials}

Data sharing is not applicable to this article as no datasets were generated or analysed during the current study. 


\section{Authors' contributions}

The ideas as presented here are the result of equal intellectual input by the authors. Both authors have read and revised the manuscript prior to submitting it to the European Journal of Futures Research. Both authors have read and approved the final manuscript.

\section{Ethics approval and consent to participate}

Not applicable.

\section{Consent for publication}

Not applicable.

\section{Competing interests}

The authors declare that they have no competing interests.

\section{Publisher's Note}

Springer Nature remains neutral with regard to jurisdictional claims in published maps and institutional affiliations.

\section{Author details}

${ }^{1}$ Cardiff University LawLab Research Centre, Cardiff, UK. ${ }^{2}$ Cardiff School of Law and Politics, Cardiff University, Museum Avenue, Cardiff CF10 3AX, UK. ${ }^{3}$ Cardiff School of Social Sciences, Cardiff University, Glamorgan Building, King Edward VII Ave, Cardiff CF10 3NN, UK.

\section{Received: 1 August 2018 Accepted: 12 November 2018} Published online: 07 December 2018

\section{References}

1. Ackoff RL (1989) From data to wisdom. J Appl Syst Anal 16:3-9

2. Ateah CA, Snow W, Wener P, MacDonald L, Metge C, Davis P, Fricke M, Ludwig S, Anderson J (2011) Stereotyping as a barrier to collaboration: does interprofessional education make a difference? Nurse Educ Today 31(2):208-213

3. Bartlett A, Lewis J, Reyes-Galindo L, Stephens N (2018) The locus of legitimate interpretation in big data sciences: lessons for computational social science from -omic biology and high-energy physics. Big Data Soc 5(1):2053951718768831

4. Björneborn L (2017) Three key affordances for serendipity: toward a framework connecting environmental and personal factors in serendipitous encounters. J Doc 73(5):1053-1081

5. Boh WF, Evaristo R, Ouderkirk A (2014) Balancing breadth and depth of expertise for innovation: a 3M story. Res Policy 43(2):349-366

6. Brassler M, Dettmers J (2017) How to enhance interdisciplinary competence-interdisciplinary problem-based learning versus interdisciplinary project-based learning. Interdisciplinary J Problem-Based Learn 11(2):12

7. Bridle H, Vrieling A, Cardillo M, Araya Y, Hinojosa L (2013) Preparing for an interdisciplinary future: a perspective from early-career researchers. Futures 53(Supplement C):22-32

8. Bruce A, Lyall C, Tait J, Williams R (2004) Interdisciplinary integration in Europe: the case of the fifth framework programme. Futures 36(4):457-470

9. Buanes A, Jentoft S (2009) Building bridges: institutional perspectives on interdisciplinarity. Futures 41(7):446-454

10. Burt RS (2009) Structural holes: the social structure of competition. Harvard University Press, Cambridge

11. Callard F, Fitzgerald D (2015a) Introduction: Not another book about Interdisciplinarity. In: Rethinking Interdisciplinarity across the social sciences and neurosciences. Palgrave Pivot, London, pp 1-14

12. Callard F, Fitzgerald D (2015b) 'Which way does it go between you two?' Modes of interdisciplinary intervention. In: Rethinking Interdisciplinarity across the social sciences and neurosciences. Palgrave Pivot, London, pp $32-45$

13. Campaign for Social Science (2018). Launch of making the case for the social sciences - accounting \& finance [online]. Eventbrite. Available from: https:/ www.eventbrite.co.uk/e/44631194103?aff=efbneb. Accessed 21 July 2018

14. Campaign for Social Science - Making the Case - Climate change [online] (2018). Campaign for Social Science. Available from: https:// campaignforsocialscience.org.uk/publications/making-the-case-climatechange/. Accessed 21 July 2018
15. Castán Broto V, Gislason M, Ehlers M-H (2009) Practising interdisciplinarity in the interplay between disciplines: experiences of established researchers. Environ Sci Pol 12(7):922-933

16. Christodoulou D (2014) Seven myths about education, 1st edn. New York: Routledge, London

17. Chur-Hansen A, Koopowitz L, Jureidini J, Abhary S, McLean S (2006) An interdisciplinary course for trainee psychiatrists: feedback and implications. Australas Psychiatry 14(2):186-191

18. Collins H (2013) Three dimensions of expertise. Phenomenol Cogn Sci 12(2): 253-273

19. Collins H, Evans R (2007) Rethinking expertise. The University of Chicago Press, Chicago

20. Conley S, Fisher E (2017) Developing a theoretical scaffolding for interactional competence: a conceptual and empirical investigation into competence versus expertise. In: SEESHOP17, Presented at the Studies of Expertise and Experience Annual Meeting, Geneva, Switzerland

21. Danermark B (2007) Interdisciplinary research and critical realism: the example of disability research. J Crit Realism 5(1):56-64

22. Darlington E, Waite C, Balsdon S (2015) Postgraduate events as a building block for interdisciplinary research. Area 47(4):481-483

23. Davies SR (2013) Research staff and public engagement: a UK study. High Educ 66(6):725-739

24. Dulic A, Angel J, Sheppard S (2016) Designing futures: inquiry in climate change communication. Futures 81:54-67

25. European Foresight Platform [online] (2018). Available from: http://www. foresight-platform.eu/. Accessed 29 Oct 2018

26. Geenhuizen M van. (2018) A framework for the evaluation of living labs as boundary spanners in innovation. Environment and Planning C: Politics and Space 36(7):1280-1298

27. Genn H, Partington M, Wheeler S (2006) Law in the real world: improving our understanding of how law works. The Nuffield Foundation, London

28. Gidley JM (2016) Understanding the breadth of futures studies through a dialogue with climate change. World Futur Rev 8(1):24-38

29. Griffin G, Medhurst P, Green T (2006) Interdisciplinarity in interdisciplinary research programmes in the UK. University of Hull, Hull

30. Heinonen S, Ruotsalainen J (2013) Futures clinique - method for promoting futures learning and provoking radical futures. Eur J Futur Res 1(1):7

31. Iansiti M (1993). Real-world R\&D: jumping the product generation gap [online]. Harvard Business Review. Available from: https://hbr.org/1993/05/ real-world-rd-jumping-the-product-generation-gap. Accessed 21 July 2018

32. Innovation Cardiff (2018). The business of people: the significance of social science to industry [online]. Cardiff University. Available from: https://www. cardiff.ac.uk/events/view/the-business-of-people-the-significance-of-socialscience-to-industry. Accessed 21 Nov 2018.

33. Klaassen RG (2018) Interdisciplinary education: a case study. Eur J Eng Educ $0(0): 1-18$

34. Knapp B, Bardenet R, Bernabeu MO, Bordas R, Bruna M, Calderhead B, Cooper J, Fletcher AG, Groen D, Kuijper B, Lewis J, Mclnerny G, Minssen T, Osborne J, Paulitschke V, Pitt-Francis J, Todoric J, Yates CA, Gavaghan D, Deane CM (2015) Ten simple rules for a successful cross-disciplinary collaboration. PLoS Comput Biol 11(4):e1004214

35. Kovács B, Hannan MT (2015) Conceptual spaces and the consequences of category spanning. Sociol Sci 2:252-286

36. Krogh, G. von, Ichijo, K., and Nonaka, l., 2000. Enabling knowledge creation: how to unlock the mystery of tacit knowledge and release the power of innovation. Oxford University Press, USA

37. Larson EL, Landers TF, Begg MD (2011) Building interdisciplinary research models: a didactic course to prepare interdisciplinary scholars and faculty. Clin Transl Sci 4(1):38-41

38. Lau L, Pasquini M (2008) 'Jack of all trades'? The negotiation of interdisciplinarity within geography. Geoforum 39:552-560

39. Lave J and Wenger E (1991) Situated learning: legitimate peripheral participation, 1st edn. New York: Cambridge University Press, Cambridge

40. Leszczyńska D, Khachlouf N (2018) How proximity matters in interactive learning and innovation: a study of the venetian glass industry. Ind Innov $0(0): 1-23$

41. Levina N, Vaast E (2005) The emergence of boundary spanning competence in practice: implications for implementation and use of information systems. MIS Q 29(2):335-363

42. Lewis J (2013) Academic governance: disciplines and policy. Routledge, New York 
43. Lewis J, Bisson S, Swaden Lewis K, Reyes-Galindo L, Baldwin A (2017) Cardiff sciSCREEN: a model for using film screenings to engage publics in university research. Res All 1(1):106-120

44. Lewis J and Watermeyer R (2018). Why universities and academics should bother with public engagement [online]. The Conversation. Available from: http://theconversation.com/why-universities-and-academics-should-botherwith-public-engagement-72550. Accessed 21 Nov 2018

45. Long JC, Cunningham FC, Braithwaite J (2013) Bridges, brokers and boundary spanners in collaborative networks: a systematic review. BMC Health Serv Res 13:158

46. Lyall C, Meagher L, Bruce A (2015) A rose by any other name? Transdisciplinarity in the context of UK research policy. Futures 65(Supplement C):150-162

47. Making the Case Archives [online] (2018). Campaign for Social Science. Available from: https://campaignforsocialscience.org.uk/publicationcategory/making-the-case/. Accessed 21 Nov 2018

48. Makri S, Blandford A (2011) What is serendipity? - a workshop report. UCL Interaction Centre: UCL, London., No. 491

49. Mallaband B, Wood G, Buchanan K, Staddon S, Mogles NM, Gabe-Thomas E (2017) The reality of cross-disciplinary energy research in the United Kingdom: a social science perspective. Energy Res Soc Sci 25(Supplement C):9-18

50. McBee D, Leahey E (2016) New directions, new challenges: trials and tribulations of interdisciplinary research. In: Investigating Interdisciplinary Collaboration: Theory and Practice across Disciplines. Rutgers University Press, pp 27-46

51. McCay-Peet L, Toms EG (2015) Investigating serendipity: how it unfolds and what may influence it. J Assoc Inf Sci Technol 66(7):1463-1476

52. Moran J (2010) Interdisciplinarity (the new critical idiom). Routledge, New York

53. Muddiman E, Bullock AD, MacDonald J, Allery L, Webb KL, Pugsley L (2016) 'It's surprising how differently they treat you': a qualitative analysis of trainee reflections on a new programme for generalist doctors. BMJ Open 6(9): e011239-e011239

54. National Academy of Sciences, National Academy of Engineering, and Institute of Medicine (2005) Facilitating interdisciplinary research. The National Academies Press, Washington, DC

55. Nesti G (2018) Co-production for innovation: the urban living lab experience. Polic Soc 37(3):310-325

56. Nowotny H (2016) Investigating interdisciplinary collaboration: theory and practice across disciplines. Rutgers University Press, New Brunswick

57. Pedersen DB (2016) Integrating social sciences and humanities in interdisciplinary research. Palgrave Commun 2:1-7

58. Pennington D (2011) Collaborative, cross-disciplinary learning and coemergent innovation in eScience teams | SpringerLink. Earth Sci Inf 4:55-68

59. Priaulx N I Ivins W, De Ribaupierre H, Morris C (2018a) The SPARC prototype: towards a socio-technical innovation designed to create collaborative connections between experts. In: SEESHOP18, Presented at the Studies of Expertise and Experience Annual Meeting, Cardiff University, Cardiff

60. Priaulx N, Weinel M (2013) Understanding "Understanding" in science communication. In: Goodwin J (ed) Ethical issues in science communication: a theory-based approach, proceedings of a conference at lowa State University. Great Plains Society for the Study of Argumentation, Ames

61. Priaulx N, Weinel M (2014) Behaviour on a beer mat: law, interdisciplinary \& expertise. Univ III J Law Technol Policy 2014:361-391

62. Priaulx N, Weinel M, and Leonard-Clarke W (2018b). How outsiders see us: multidisciplinary understandings of legal academia and legal academics. Cardiff University LawLab Working Paper. https://sites.cardiff.ac.uk/law-lab/ lawlab-collaborative-research/lawlab-working-paper-series/. Accessed 21 Nov 2018

63. Ramos JM (2010) Movements toward holism in futures inquiry. Futures 42(2):115-124

64. REF (2014). REF Case study search [online]. REF 2014 Impact Case Studies. Available from: https://impact.ref.ac.uk/casestudies/. Accessed 7 Nov 2018

65. van Rijnsoever FJ, Hessels LK (2011) Factors associated with disciplinary and interdisciplinary research collaboration. Res Policy 40(3):463-472

66. Safford HD, Sawyer SC, Kocher SD, Hiers JK, Cross M (2017) Linking knowledge to action: the role of boundary spanners in translating ecology. Front Ecol Environ 15(10):560-568

67. Vick DW (2004) Interdisciplinarity and the discipline of law. J Law Soc 31(2): 163-193
68. Weinel M (2007) Primary source knowledge and technical decision-making: Mbeki and the AZT debate. Stud Hist Phil Sci 38:748-760

69. Wenger $E$ (2000) Communities of practice: learning, meaning, and identity. New Ed edition. Cambridge University Press, Cambridge

70. Williams P (2002) The competent boundary spanner. Public Adm 80(1):103-124

\section{Submit your manuscript to a SpringerOpen ${ }^{\circ}$ journal and benefit from:}

- Convenient online submission

- Rigorous peer review

- Open access: articles freely available online

High visibility within the field

- Retaining the copyright to your article

Submit your next manuscript at $>$ springeropen.com 